\title{
Nano-structuring in SiGe by oxidation induced anisotropic Ge self-organization
}

Ethan Long, , Augustinas Galeckas, , Andrej Yu Kuznetsov, , Antoine Ronda, , Luc Favre, , Isabelle Berbezier, and, and Henry H. Radamson

Citation: Journal of Applied Physics 113, 104310 (2013); doi: 10.1063/1.4794991

View online: http://dx.doi.org/10.1063/1.4794991

View Table of Contents: http://aip.scitation.org/toc/jap/113/10

Published by the American Institute of Physics

\section{Articles you may be interested in}

Oxidation rate enhancement of SiGe epitaxial films oxidized in dry ambient

Applied Physics Letters 83, 3713 (2003); 10.1063/1.1622439

Effects of Ge concentration on SiGe oxidation behavior

Applied Physics Letters 59, 1200 (1998); 10.1063/1.105502

Oxidation studies of SiGe

Journal of Applied Physics 65, 1724 (1998); 10.1063/1.342945

\section{AlP $\left.\right|_{\text {Applied Physics }} ^{\text {Journal of }}$}

Save your money for your research.

It's now FREE to publish with us no page, color or publication charges apply.
Publish your research in the

Joumal of Applied Physics

to claim your place in applied

physics history. 


\title{
Nano-structuring in SiGe by oxidation induced anisotropic Ge self-organization
}

\author{
Ethan Long, ${ }^{1, a)}$ Augustinas Galeckas, ${ }^{1}$ Andrej Yu Kuznetsov, ${ }^{1}$ Antoine Ronda, ${ }^{2}$ \\ Luc Favre, ${ }^{2}$ Isabelle Berbezier, ${ }^{2}$ and Henry H. Radamson ${ }^{3}$ \\ ${ }^{1}$ University of Oslo, Blindern, 0316 Oslo, Norway \\ ${ }^{2}$ Univ. Aix Marseille, Campus St. Jérôme, 13397 Marseille Cedex 20, France \\ ${ }^{3}$ Royal Institute of Technology (KTH), Electrum 29, 16440 Kista, Sweden
}

(Received 31 January 2013; accepted 25 February 2013; published online 14 March 2013)

\begin{abstract}
The present study examines the kinetics of dry thermal oxidation of (111), (110), and (100) silicon-germanium ( $\mathrm{SiGe}$ ) thin epitaxial films and the redistribution of $\mathrm{Ge}$ near the oxidation interface with the aim of facilitating construction of single and multi-layered nano-structures. By employing a series of multiple and single step oxidations, it is shown that the paramount parameter controlling the Ge content at the oxidation interface is the oxidation temperature. The oxidation temperature may be set such that the Ge content at the oxidation interface is increased, kept static, or decreased. The Ge content at the oxidation interface is modeled by considering the balance between $\mathrm{Si}$ diffusion in $\mathrm{SiGe}$ and the flux of $\mathrm{Si}$ into the oxide by formation of $\mathrm{SiO}_{2}$. The diffusivity of $\mathrm{Si}$ in $\mathrm{SiGe}$ under oxidation is determined for the three principal crystal orientations by combining the proposed empirical model with data from X-ray diffraction and variable angle spectroscopic ellipsometry. The orientation dependence of the oxidation rate of SiGe was found to follow the order: $(111)>(110)>(100)$. The role of crystal orientation, Ge content, and other factors in the oxidation kinetics of $\mathrm{SiGe}$ versus $\mathrm{Si}$ are analyzed and discussed in terms of relative oxidation rates. (C) 2013 American Institute of Physics. [http://dx.doi.org/10.1063/1.4794991]
\end{abstract}

\section{INTRODUCTION}

There is significant research and industrial interest in silicon-germanium ( $\mathrm{SiGe}$ ) based nano-structures and devices. ${ }^{1}$ Among numerous examples of how $\mathrm{SiGe}$, in general, and $\mathrm{Ge}$ condensation by thermal oxidation of $\mathrm{SiGe}$, in particular, may be used for fabrication of nano-scale devices are: monolithically integrated optical interconnects and waveguides, ${ }^{2}$ nano-antennas, ${ }^{3}$ bolometers for uncooled infrared photodetectors, ${ }^{4,5}$ nano-crystals for use in high density nonvolatile memories, ${ }^{6,7}$ multiple gate field effect transistors (including FinFETs) ${ }^{8-11}$ and nano-wires. ${ }^{12,13}$ Achieving a direct bandgap in SiGe core-shell nanowires depends on, among other things, the nanowire's orientation and shell thickness. ${ }^{14-16}$ Local oxidation of SiGe has long been proposed as a method to manipulate the Ge content in the channel or source/drain regions of transistors, which, in addition to the performance benefits, may help reduce manufacturing costs and cycle times by eliminating steps from $\mathrm{SiGe} \mathrm{CMOS}$ processes. ${ }^{17} \mathrm{SiGe}-$ on-insulator (SGOI) is a viable replacement for bulk Si in deep sub-micron CMOS applications, ${ }^{18}$ and the fabrication of SGOI wafers using Ge condensation by thermal oxidation ${ }^{19}$ as well as by thermally induced $\mathrm{Ge}$ dilution ${ }^{20}$ has been suggested. Use of thermal oxidation for SGOI fabrication may also allow for endotaxial growth of high Ge content layers and Ge nano-crystals at the interface between a buried oxide and a SiGe layer. ${ }^{21}$ A sound understanding of the oxidation of SiGe in multiple crystallographic orientations will be required to develop processes for using $\mathrm{SiGe}$ in such applications.

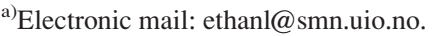

The two phenomena commonly discussed in the literature about oxidation of SiGe are the potential for Ge to act as a catalyst or inhibitor for oxidation, and the formation of a Ge-rich layer between the oxide and the underlying SiGe, referred to as Ge condensation, pile-up, or snow plowing. ${ }^{22-30}$ A common explanation for the presumed catalytic effect of Ge relies on the dissociation energy for a $\mathrm{Si}-\mathrm{Ge}$ bond being lower than that of a Si-Si bond, ${ }^{31-35}$ while others explain Ge's role as a catalyst in terms of the generation of vacancies and interstitials in the SiGe layers. ${ }^{22-25,36-38}$ However, conclusions about the role of $\mathrm{Ge}$ in determining the oxidation rate vary widely, and the Ge content at the oxidation interface is rarely characterized in a systematic way. ${ }^{39}$ Furthermore, except for an early study using (111) oriented material, ${ }^{40}$ oxidation of SiGe has been studied with an exclusive focus on (100) material. The orientation dependence of oxidation of $\mathrm{Si}^{41-43}$ may be an indication that $\mathrm{SiGe}$ will exhibit similar behaviour, but it is not obvious that $\mathrm{SiGe}$ and $\mathrm{Si}$ are perfectly synonymous in this respect. It has been established that oxidation enhanced diffusion of dopants in $\mathrm{Si}$ is tied to both point defects and crystallographic orientation. ${ }^{44,45}$ If point defects play a role in Si diffusion in $\mathrm{SiGe},{ }^{22,38,46}$ then it is likely that any oxidation enhanced diffusion of $\mathrm{Si}$ in $\mathrm{SiGe}$ due to point defects is also orientation dependent. By virtue of the dependence of the $\mathrm{Ge}$ condensation on the diffusivity of $\mathrm{Si}$ in $\mathrm{SiGe},{ }^{26,27}$ any orientation dependence in the latter will have a direct consequence on the Ge content at the oxidation interface.

The present study evaluates the kinetics of oxidation of SiGe with (111), (110), and (100) oriented thin epitaxial films of SiGe. The possibility to increase, keep stable, or decrease the Ge content at the oxidation interface is demonstrated by using 
X-ray diffraction (XRD) characterization of SiGe samples after multiple oxidations. Characterization of samples with a range of oxide thicknesses and oxidation temperatures shows that the Ge content in the pile-up region is strongly dependent on oxidation temperature and only weakly dependent on the Ge content in the underlying SiGe. Lower oxidation temperatures are shown to be linearly correlated to higher Ge contents, though the linear temperature dependence of $\mathrm{Ge}$ content varies with crystallographic orientation. The Ge content at the oxidation interface is modeled by an empirical relationship which considers the balance between $\mathrm{Si}$ diffusion in $\mathrm{SiGe}$ and $\mathrm{Si}$ flux into the oxide by formation of $\mathrm{SiO}_{2}$. The diffusivity parameters of $\mathrm{Si}$ in SiGe under oxidation are determined for the principal crystal orientations. The oxidation rates of both $\mathrm{Si}$ and $\mathrm{SiGe}$ are found to be dependent on the crystallographic orientation as well as the presence of Ge at the oxidation interface. The degree of growth rate enhancement or reduction is discussed in terms of oxidation rate ratios.

\section{EXPERIMENTAL}

Epitaxial layers of $\mathrm{Si}_{1-X} \mathrm{Ge}_{X}$ were grown on (111), (110), and (100) oriented Si substrates by molecular beam epitaxy (MBE). The as-grown SiGe layers were composed of $20 \% \mathrm{Ge}$, while a supplementary set of (100) oriented samples contained $15 \% \mathrm{Ge}$. Additionally, a set of (100) oriented samples with $\mathrm{Si}_{0.8} \mathrm{Ge}_{0.2}$ layers were grown by chemical vapor deposition (CVD). The CVD grown samples were used exclusively for experiments involving repeated oxidations. Those samples which were subjected to repeated oxidations had their oxides removed by a timed buffered hydrofluoric acid etch between each oxidation. All as-grown $\mathrm{Si}_{1-X} \mathrm{Ge}_{X}$ layers had thicknesses of $\sim 80 \mathrm{~nm}$. Bare Si substrates were used as reference samples for all oxidation runs.

The thermal oxidations were carried out at ambient pressure $(1 \mathrm{~atm})$ in a tube furnace flushed with dry $\mathrm{O}_{2}$. For any given oxidation time and temperature, all samples were processed simultaneously in order to ensure identical oxidation conditions between samples with various characteristics (i.e., SiGe, $\mathrm{Si}$, crystal orientation). Oxidations for (111), (110), and (100) oriented samples were carried out at 900,950 , and $1000^{\circ} \mathrm{C}$ with oxidation times chosen to target $20,40,60,80$, and $100 \mathrm{~nm}$ thick oxides. Supplementary (100) oriented $\mathrm{Si}_{0.85} \mathrm{Ge}_{0.15}$ and $\mathrm{Si}_{0.80} \mathrm{Ge}_{0.20}$ samples were oxidized at 780, 820, 870, 920, or $960^{\circ} \mathrm{C}$ to grow oxides between 0 and $60 \mathrm{~nm}$ thick.

XRD measurements were made with a diffractometer in double axis configuration. The incident beam was composed of $\mathrm{Cu}-\mathrm{K}_{\alpha 1}$ radiation, while $\mathrm{Cu}-\mathrm{K}_{\alpha 2 .}$ and $\mathrm{Cu}-\mathrm{K}_{\beta}$ radiation was removed with a Göbel mirror and Ge monochromator. The peaks for the $2 \theta-\omega$ scans were chosen according to sample orientation, i.e., the (004) peak for (100), the (333) peak for (111), and both (022) and (044) peaks for (110) oriented material. The profiles from the $2 \theta-\omega$ scans were fit using a 3-layer model, lattice constants from Dismukes et al. ${ }^{47}$ and the LEPTOS simulation software. Reciprocal space maps of a limited number of samples confirmed that the SiGe layers were pseudomorphically strained before and after oxidation.

Oxide thicknesses were measured by variable angle spectroscopic ellipsometry. Measurements were recorded at $65^{\circ}, 70^{\circ}$, and $75^{\circ}$ with photon energies varied between 1.39 and $3.25 \mathrm{eV}$ in increments of $0.01 \mathrm{eV}$. Oxide thicknesses were determined using a multi-layer model, optical constants for $\mathrm{SiO}_{2}, \mathrm{Si}$, and $\mathrm{SiGe}$ from literature, ${ }^{48,49}$ and the COMPLETEEASE software.

\section{RESULTS AND DISCUSSION}

\section{A. Ge content in the pile-up}

A series of multi-step oxidations was performed to highlight the relative influence of temperature and initial Ge content on the pile-up of Ge at the oxidation interface. Figure 1 shows XRD scans for $\mathrm{Si}_{0.8} \mathrm{Ge}_{0.2}$ samples subjected to one, two, and three separate oxidations at progressively lower temperatures. The XRD scans are aligned to the $\mathrm{Si}$ substrate peak at $69.13^{\circ}$. The peak at $68.10^{\circ}$ arises from the as-grown SiGe layer and reflects the $20 \% \mathrm{Ge}$ content of the layer. The left most peaks correspond to the Ge pile-up layers that form as a result of the oxidations. After oxidation, the intensity of the XRD peak for the as-grown layer will be reduced as a result of the thinning of the layer. For the oxidized samples in Fig. 1, the oxide and pile-up layers were thick enough so that any extant signal from the as-grown layer is obscured. The shift in the $2 \theta$ position of the pile-up peaks from high to low angles indicates an increase in the Ge content of the pile-up layer, $X_{\mathrm{pu}}$. The first sample was subjected to a singlestep oxidation at $1000^{\circ} \mathrm{C}$, which resulted in $X_{\mathrm{pu}}=0.310$. The second sample was subjected to a two-step oxidation: the same oxidation at $1000^{\circ} \mathrm{C}$ and a subsequent second oxidation at $900^{\circ} \mathrm{C}$, resulting in $X_{\mathrm{pu}}=0.466$. The third sample underwent a three-step oxidation at 1000, 900, and then $800^{\circ} \mathrm{C}$, resulting in $X_{\mathrm{pu}}=0.572$. Despite the Ge content at the oxidation interface increasing with multiple oxidations at progressively lower temperatures, $T$, these results are consistent with what is predicted by empirical relations for $X_{\mathrm{pu}}(T)$ that are based on single oxidations of $\mathrm{Si}_{0.80} \mathrm{Ge}_{0.20}$ and

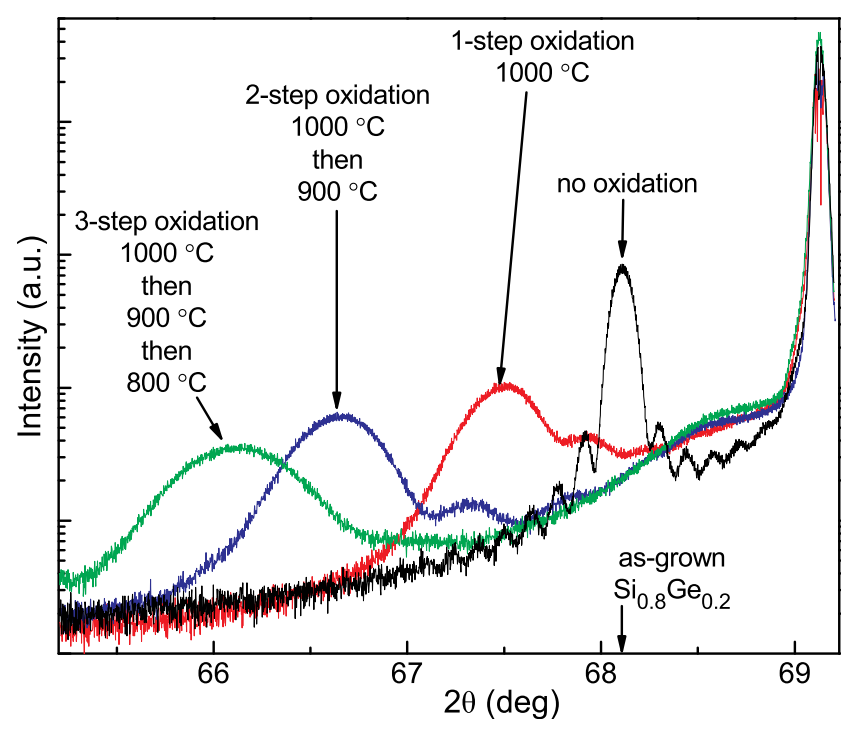

FIG. 1. XRD scans of the (004) peaks of (100) oriented SiGe samples after multi-step oxidations with decreasing temperatures. The $2 \theta$ position for the as-grown sample is marked for reference. 


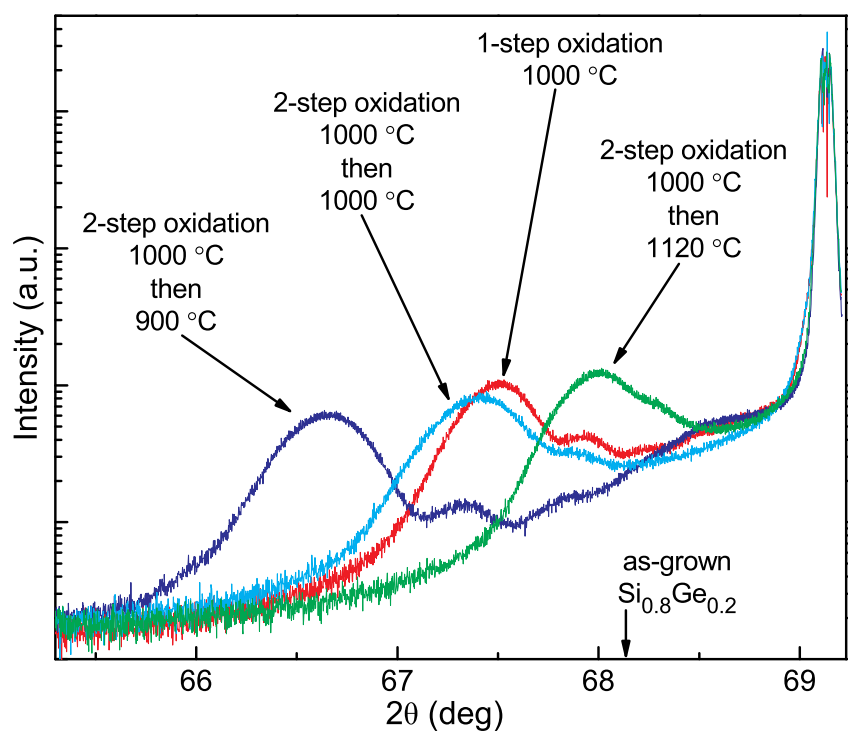

FIG. 2. XRD scans of the (004) peaks of (100) oriented SiGe samples after various multi-step oxidation schemes. The $2 \theta$ positions of the peaks indicate an increase, no change, and a decrease in $X_{\text {pu }}$. The scan for the as-grown sample is omitted for clarity, but its $2 \theta$ position is marked for reference.

$\mathrm{Si}_{0.85} \mathrm{Ge}_{0.15}$ alloys. $^{27}$ That is, the value of $X_{\mathrm{pu}}$ depends critically on the oxidation temperature, and is largely independent of the Ge content in the underlying SiGe. In the case of multiple oxidations at progressively lower temperatures, the Ge content at the oxidation interface, $X_{\mathrm{pu}}$, is primarily determined by the temperature of the last oxidation performed, despite the progressively increasing $X_{\mathrm{pu}}$.

Figure 2 shows XRD scans of $\mathrm{Si}_{0.8} \mathrm{Ge}_{0.2}$ samples subjected to a similar scheme of multi-step oxidations. A set of four samples was first oxidized at $1000^{\circ} \mathrm{C}$ in order to create a thick pile-up layer with $X_{\mathrm{pu}}=0.310$. Three samples were subsequently subjected to an additional oxidation step at 1120,1000 , or $900^{\circ} \mathrm{C}$. These temperatures were chosen to induce a decrease, no change, and an increase in $X_{\mathrm{pu}}$ by following the previously published analysis for single oxidations of $\mathrm{SiGe}(100){ }^{27}$ Indeed, the XRD scans in Fig. 2 reveal that the secondary oxidations at 1120, 1000, and $900{ }^{\circ} \mathrm{C}$ have caused $X_{\text {pu }}$ to shift from 0.310 to $0.217,0.331$, and 0.466 , respectively. As stated above, $X_{\mathrm{pu}}$ is determined primarily by the temperature of the last oxidation conducted. However, the $\mathrm{Ge}$ content at the oxidation interface is increased from 0.20 to 0.31 after the first oxidation at $1000{ }^{\circ} \mathrm{C}$. The higher Ge content at the oxidation interface at the start of the second oxidation had the consequence of increasing $X_{\mathrm{pu}}$ by $\sim 2 \%$ after the second oxidation at $1000{ }^{\circ} \mathrm{C}$. This effect is evident in the empirical relation for $X_{\mathrm{pu}}\left(T, N_{\mathrm{SiGe}}\right)^{27}$ (also in Eq. (1)), where $N_{\mathrm{SiGe}}$ is the Si density in the primary SiGe layer.

An additional series of oxidations was conducted on SiGe and Si samples to investigate the influence of crystallographic orientation on the formation of the pile-up region and on the oxidation kinetics of SiGe. These oxidation runs involved a single oxidation of as-grown $\mathrm{Si}_{0.8} \mathrm{Ge}_{0.2}$ and $\mathrm{Si}$ samples, though a variety of oxidation temperatures and times were used for different oxidation runs. Figure 3 shows the oxide thickness versus oxidation time for 900, 950, and $1000{ }^{\circ} \mathrm{C}$. The oxidation rates are ordered as $(111)>(110)>$ (100) for both $\mathrm{Si}$ and SiGe. Most of the oxidation runs performed at 900 and $1000{ }^{\circ} \mathrm{C}$ result in $\mathrm{SiGe}$ oxidizing faster than $\mathrm{Si}$, but the longer oxidations at $950{ }^{\circ} \mathrm{C}$ and the $360 \mathrm{~min}$ oxidation at $900^{\circ} \mathrm{C}$ show $\mathrm{Si}$ oxidizing faster than $\mathrm{SiGe}$.

Figure 4 shows typical results of XRD measurements performed to quantify $X_{\text {pu }}$ for the samples described in Fig. 3. There are three distinct peak positions: the substrate peak at $\sim 95^{\circ}$, the peaks at $\sim 93.8^{\circ}$ from the primary SiGe layers, and the leftmost peaks corresponding to the pile-up layers. The pile-up layer peaks are distinguished by their separation according to oxidation temperature, while oxide thickness does not have a profound influence on $X_{\mathrm{pu}}$.

The dependence of $X_{\mathrm{pu}}$ on crystallographic orientation and temperature is illustrated in Fig. 5. Even though $X_{\mathrm{pu}}(T)$ is orientation dependent, linear fits to the measured values reveal nearly identical slopes for all three orientations.

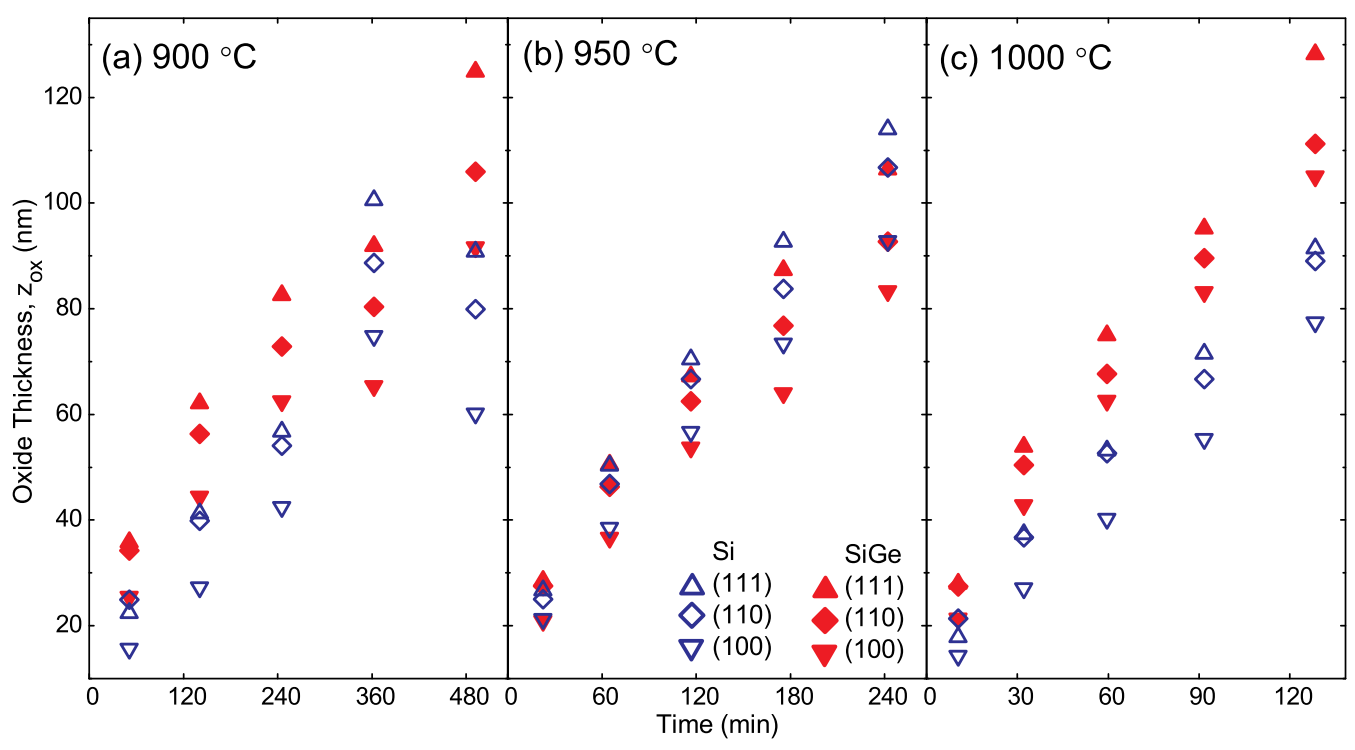

FIG. 3. Oxide thickness versus oxidation time at (a) 900 , (b) 950 , and (c) $1000^{\circ} \mathrm{C}$. The data are for (111), (110), and (100) oriented $\mathrm{Si}_{0.8} \mathrm{Ge}_{0.2}$ and $\mathrm{Si}_{\text {. }}$ 


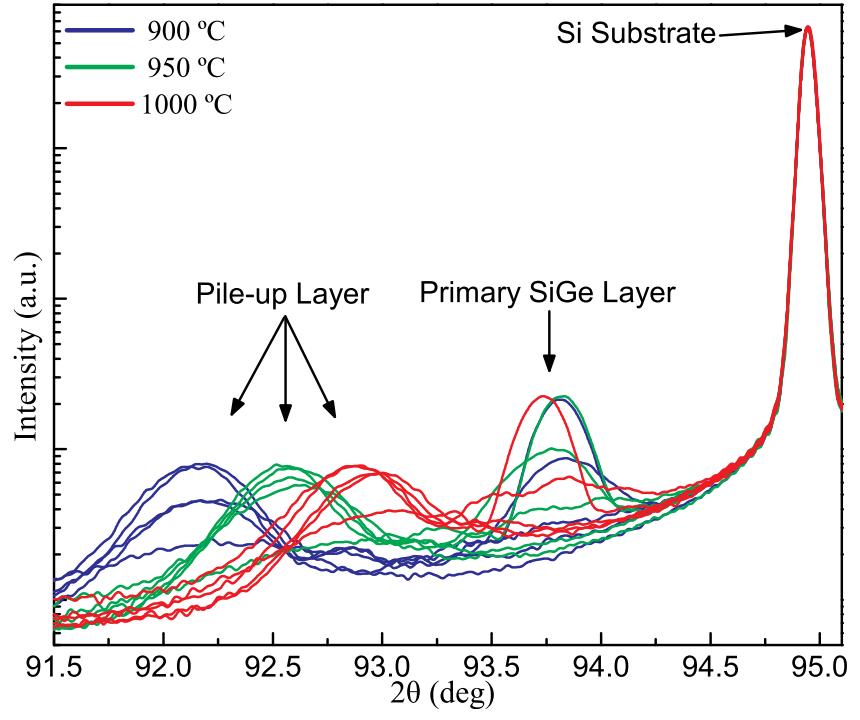

FIG. 4. XRD $2 \theta-\omega$ scans of the (333) peaks of (111) oriented $\mathrm{Si}_{0.8} \mathrm{Ge}_{0.2}$ oxidized at various temperatures and times. Five samples with oxide thicknesses between 20 and $100 \mathrm{~nm}$ are shown for each temperature.

\section{B. Diffusivity of $\mathrm{Si}$ in SiGe and the oxidation rate}

As detailed in earlier publications, ${ }^{26,27}$ the magnitude of $X_{\mathrm{pu}}$ results from the diffusion induced flux of Si towards the oxidation front, $J_{\mathrm{pu}}$, and the flux of $\mathrm{Si}$ into the oxide due to formation of $\mathrm{SiO}_{2}, J_{\mathrm{ox}}$, being balanced such that $J_{\mathrm{ox}} / J_{\mathrm{pu}}=1$. Thus, changes to the oxidation rate must be matched by changes to the diffusion of $\mathrm{Si}$ in $\mathrm{SiGe}$, which appears as a change in $X_{\mathrm{pu}}$. It is well established in the literature that the oxidation rate of $\mathrm{Si}$ depends on its crystallographic orientation, ${ }^{41,50-53}$ and the data in Fig. 3 confirm that this is also true for SiGe. Furthermore, the orientation dependent diffusivity of dopants observed in $\mathrm{Si}$ under oxidation ${ }^{44,45}$ may indicate that the diffusivity of $\mathrm{Si}$ in $\mathrm{SiGe}$ is also orientation dependent. Consequently, the orientation dependence of both the oxidation rate of SiGe and the diffusivity of $\mathrm{Si}$ in SiGe will alter the flux balance, $J_{\mathrm{ox}} / J_{\mathrm{pu}}=1$, and thus, modify $X_{\mathrm{pu}}(T)$.

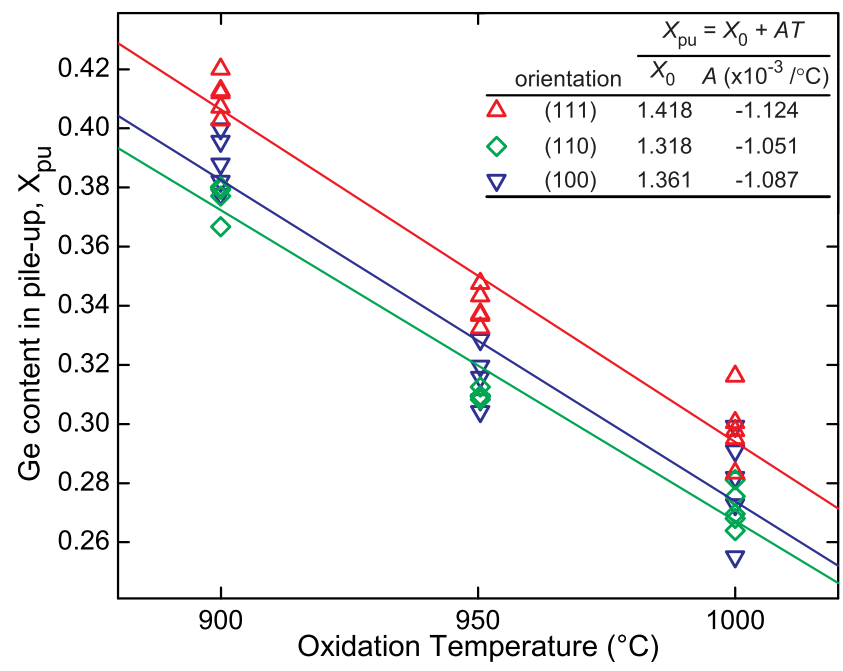

FIG. 5. XRD measurements of the Ge content in the pile-up layer, $X_{\mathrm{pu}}$, versus oxidation temperature, $T$, along with linear fits to the data.
TABLE I. Parameters for diffusivity of $\mathrm{Si}$ in SiGe for different orientations.

\begin{tabular}{lll}
\hline \hline Orientation & $E_{\mathrm{m}}(\mathrm{eV})$ & $D_{0}\left(\mathrm{~cm}^{2} / \mathrm{s}\right)$ \\
\hline 111 & -1.81 & 199 \\
110 & -1.89 & 219 \\
100 & -1.70 & 239 \\
\hline \hline
\end{tabular}

The diffusivities of Si in (111), (110), and (100) oriented $\mathrm{SiGe}$ are determined by comparing values for $X_{\mathrm{pu}}$ as measured by XRD to values calculated with the empirical relation $^{27}$

$$
X_{\mathrm{pu}}=\frac{\mathrm{k}_{\mathrm{B}} T \ln \left(\frac{4 N_{\mathrm{SiGe}}^{2} D_{0} t}{\pi N_{\mathrm{ox}}^{2} z_{\mathrm{ox}}^{2}}\right)-E_{\mathrm{Si}}}{E_{\mathrm{m}}},
$$

where $z_{\mathrm{ox}}$ is the oxide thickness from ellipsometry, $T$ is the oxidation temperature, $t$ is the oxidation time, $N_{\text {ox }}$ $=2.21 \times 10^{22} \mathrm{~cm}^{-3}$ is the atomic density of $\mathrm{Si}$ in $\mathrm{SiO}_{2}$, $N_{\mathrm{SiGe}}$ is the $\mathrm{Si}$ density in the primary $\mathrm{SiGe}$ layer, and $\mathrm{k}_{\mathrm{B}}$ is the Boltzmann constant. The diffusivity of $\mathrm{Si}$ in $\mathrm{SiGe}$ is described by an Arrhenius relation, $D=D_{0} \exp \left[-\left(E_{\mathrm{m}} X_{\mathrm{pu}}\right.\right.$ $\left.\left.+E_{\mathrm{Si}}\right) /\left(\mathrm{k}_{\mathrm{B}} T\right)\right]$, where the same activation energy for Si selfdiffusion, $E_{\mathrm{Si}}=4.76 \mathrm{eV},{ }^{54}$ is used for all three crystallographic orientations. The diffusion parameters $D_{0}$ and $E_{\mathrm{m}}$ were determined independently for the (111), (110), and (100) orientations by fitting the calculated and measured values of $X_{\mathrm{pu}}$ using the method of least squares; the results are summarized in Table I. The correlation between measured and calculated results for $X_{\mathrm{pu}}$ is shown in Fig. 6.

The apparent linearity of $X_{\mathrm{pu}}(T)$ in Fig. 5 can be understood if one models both the diffusivity of $\mathrm{Si}$ in $\mathrm{SiGe}$ and the oxidation rate by Arrhenius relations. Although more refined oxidation models exist, for the range of oxide thicknesses considered here, a simple Arrhenius relation is consistent with the literature $e^{41,51-53}$ and appears as an obvious choice when evaluating the balance of Si fluxes, $J_{\mathrm{ox}} / J_{\mathrm{pu}}=1$. Thus,

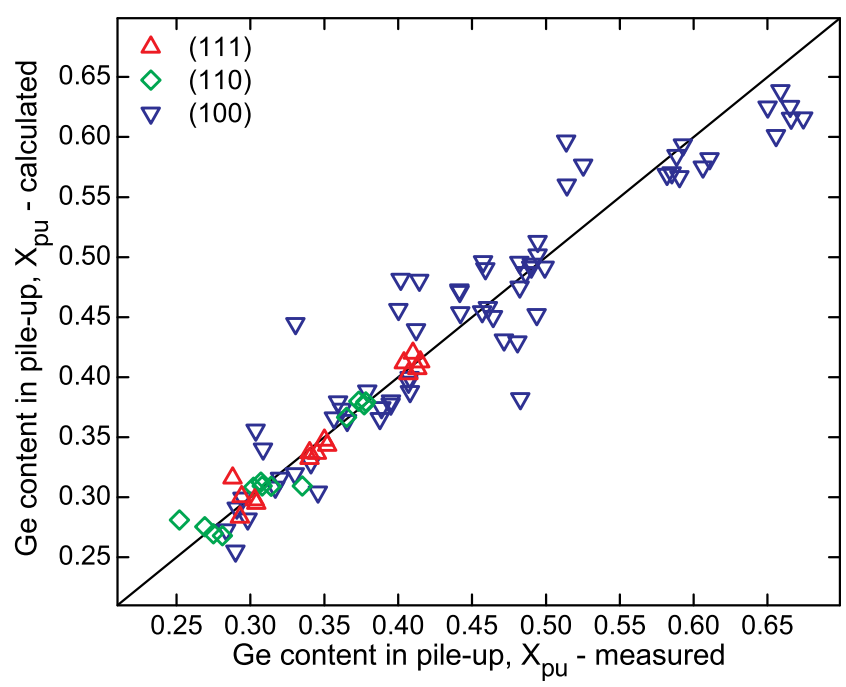

FIG. 6. Correlation between $X_{\mathrm{pu}}$ values measured by XRD and those calculated by Eq. (1). The diagonal line indicates where the measured and calculated values are exactly equal and is drawn for visual guidance only. 


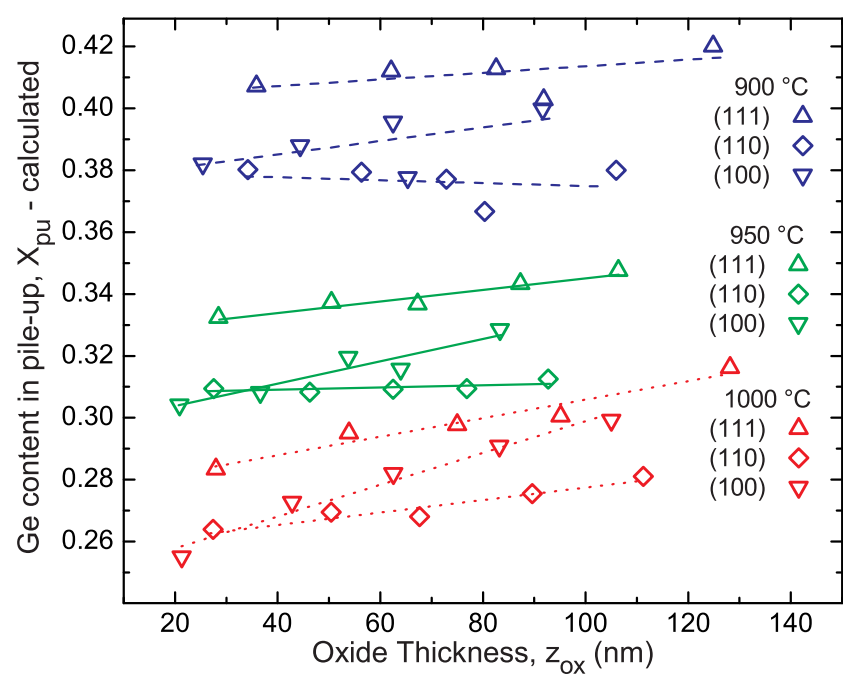

FIG. 7. The Ge content in the pile-up layer, $X_{\mathrm{pu}}$, versus oxide thickness, $z_{\mathrm{ox}}$. The lines are for visual guidance only.

by defining the oxidation rate as $\nu=\nu_{0} \exp \left[-E_{\mathrm{ox}} /\left(\mathrm{k}_{\mathrm{B}} T\right)\right]$, Eq. (1) can be rewritten as

$$
X_{\mathrm{pu}}=\frac{\mathrm{k}_{\mathrm{B}} T \ln \left(\frac{4 N_{\mathrm{SiGe}}^{2} D_{0}}{\pi N_{\mathrm{ox}}^{2} \nu_{0}^{2} t}\right)-E_{\mathrm{Si}}+2 E_{\mathrm{ox}}}{E_{\mathrm{m}}} .
$$

The logarithmic dependence on time is consistent with the observation that, for any given temperature and orientation, $X_{\text {pu }}$ remains nearly constant for a variety of oxide thicknesses, as is clearly shown in Fig. 7.

\section{Oxidation rate ratios}

A number of factors, including crystalline orientation, Ge at the oxidation front, oxidant partial pressure, and oxidant chemistry, will have varying influences on the oxidation rate, and their influences are reflected by $\nu_{0}$ and $E_{\mathrm{ox}}$. Considering the ratio of two Arrhenius functions (i.e., two oxidation rates) will highlight a single factor's contribution to $\nu_{0}$ and $E_{\mathrm{Ox}}$. So, in order to facilitate analysis of the data in Fig. 3, oxidation rate ratios are used to compare the influence of Ge content and crystal orientation on the oxidation rate. These ratios are defined here as $\rho_{a / b}=\nu_{a} / \nu_{b}$, where $\nu_{a}$ and $\nu_{b}$ are the oxidation rates for two samples with identical oxidation conditions, and a single differentiating parameter indicated by the subscripts. The average values of $\rho_{\mathrm{SiGe} / \mathrm{Si}}$ are listed in Table II, while the average oxidation rate ratios comparing (111), (110), and (100) material are reported in Table III.

The values of $\rho_{\mathrm{SiGe} / \mathrm{Si}}$ listed in Table II indicate Ge induced oxidation rate enhancement $\left(\rho_{\mathrm{SiGe} / \mathrm{Si}}>1\right)$ for 900 and $1000{ }^{\circ} \mathrm{C}$, while $950{ }^{\circ} \mathrm{C}$ indicates $\mathrm{Ge}$ induced oxidation rate reduction $\left(\rho_{\mathrm{SiGe} / \mathrm{Si}}<1\right)$. The samples oxidized for $360 \mathrm{~min}$ at $900{ }^{\circ} \mathrm{C}$ (see Fig. 3) also show $\rho_{\mathrm{SiGe} / \mathrm{Si}}<1$, while the (111) and (110) oriented samples oxidized at $950{ }^{\circ} \mathrm{C}$ for 22.5 minutes show $\rho_{\mathrm{SiGe} / \mathrm{Si}}>1$. Dry oxidations are typically not completely free of $\mathrm{H}_{2} \mathrm{O}$ or $\mathrm{N}_{2}$ due to contamination from the room ambient by diffusion through the wall of the furnace or by back-flow from the end of the furnace. ${ }^{51,53,55}$ So,
TABLE II. Oxidation rate ratios, $\rho_{\mathrm{SiGe} / \mathrm{Si}}$, comparing $\mathrm{SiGe}$ to $\mathrm{Si}$. The values are averages for all oxidation times for each combination of temperature and orientation.

\begin{tabular}{llll}
\hline \hline & & \multicolumn{2}{c}{$\rho_{\mathrm{SiGe} / \mathrm{Si}}$} \\
\cline { 2 - 4 }$T\left({ }^{\circ} \mathrm{C}\right)$ & 111 & 110 & 100 \\
\hline 780 & $\ldots$ & $\ldots$ & 1.02 \\
820 & $\ldots$ & $\ldots$ & 1.18 \\
870 & $\ldots$ & $\ldots$ & 1.07 \\
900 & 1.40 & 1.29 & 1.47 \\
920 & $\ldots$ & $\ldots$ & 1.17 \\
950 & 0.98 & 0.96 & 0.93 \\
960 & $\ldots$ & $\ldots$ & 1.19 \\
1000 & 1.46 & 1.33 & 1.55 \\
\hline \hline
\end{tabular}

the most likely explanation for the aberrations in the relative oxidation rates of $\mathrm{SiGe}$ and $\mathrm{Si}$ shown in Table II and Fig. 3 is contamination of the oxidizing ambient by some combination of $\mathrm{H}_{2} \mathrm{O}$ and $\mathrm{N}_{2}$. Furthermore, a variation in ambient chemistry seems to be the only plausible explanation for the relatively small values of $\rho_{110 / 100}$ and $\rho_{111 / 100}$ and the relatively large value of $\rho_{111 / 110}$ for $\mathrm{Si}$ at $950^{\circ} \mathrm{C}$ in Table III.

The notion that oxidant chemistry is a determining factor in the magnitude of $\rho_{\mathrm{SiGe} / \mathrm{Si}}$ is supported by studies of SiGe oxidation in dry, wet, $\mathrm{N}_{2}$ diluted, fluorinated, ozone, and atomic oxygen ambients. ${ }^{25,36,56,57}$ LeGoues et al. ${ }^{36} \mathrm{dem}-$ onstrated explicitly that $\rho_{\mathrm{SiGe} / \mathrm{Si}}>1$ for steam oxidation, whereas an ambient with $\mathrm{H}_{2} \mathrm{O}$ diluted by $\mathrm{N}_{2}$ can result in $\rho_{\mathrm{SiGe} / \mathrm{Si}} \approx 1$. In fact, modification of the oxidation ambient chemistry may simply be viewed as a way to control the various elements and molecules present at the interface between the oxide and the underlying $\mathrm{Si}$ or $\mathrm{SiGe}$. Introduction of impurities by doping with boron, phosphorus, arsenic, or antimony, ${ }^{53,58}$ alloying with carbon, ${ }^{59,60}$ or directly depositing copper $^{61}$ also have a catalytic or inhibitive effect on the oxidation of $\mathrm{Si}$ or $\mathrm{SiGe}$, and may influence the magnitude of $\rho_{\mathrm{SiGe} / \mathrm{Si}}$.

The data plotted in Fig. 3 and summarized in Table III indicate that the oxidation rates of the three orientations tend to be ordered as $(111)>(110)>(100)$. Also, a decrease in $\rho_{a / b}$ as temperature increases is an indication that $E_{\mathrm{ox}}$ is larger for the orientation given by $b$ than it is for the orientation given by $a .^{53}$ It may be observed that $\rho_{a / b}$ in Table III tends to decrease as temperature increases, which would indicate that the magnitudes of $E_{\mathrm{ox}}$ are ordered $(111)<$ $(110)<(100)$ for both $\mathrm{Si}$ and SiGe. This is consistent with the observed ordering of the oxidation rates, however, the

TABLE III. Oxidation rate ratios, $\rho_{110 / 100}, \rho_{111 / 100}$, and $\rho_{111 / 110}$, for the stated orientations. The values are averages for $\mathrm{Si}$ or $\mathrm{SiGe}$ (as indicated) for the five oxidation times used at each temperature.

\begin{tabular}{lcccccc}
\hline \hline$T\left({ }^{\circ} \mathrm{C}\right)$ & $\begin{array}{c}\rho_{110 / 100} \\
\mathrm{Si}\end{array}$ & $\begin{array}{c}\rho_{110 / 100} \\
\mathrm{SiGe}\end{array}$ & $\begin{array}{c}\rho_{111 / 100} \\
\mathrm{Si}\end{array}$ & $\begin{array}{c}\rho_{111 / 100} \\
\mathrm{SiGe}\end{array}$ & $\begin{array}{c}\rho_{111 / 110} \\
\mathrm{Si}\end{array}$ & $\begin{array}{c}\rho_{111 / 110} \\
\mathrm{SiGe}\end{array}$ \\
\hline 900 & 1.37 & 1.23 & 1.43 & 1.38 & 1.05 & 1.13 \\
950 & 1.17 & 1.21 & 1.26 & 1.33 & 1.08 & 1.10 \\
1000 & 1.30 & 1.14 & 1.28 & 1.23 & 0.99 & 1.09 \\
\hline \hline
\end{tabular}




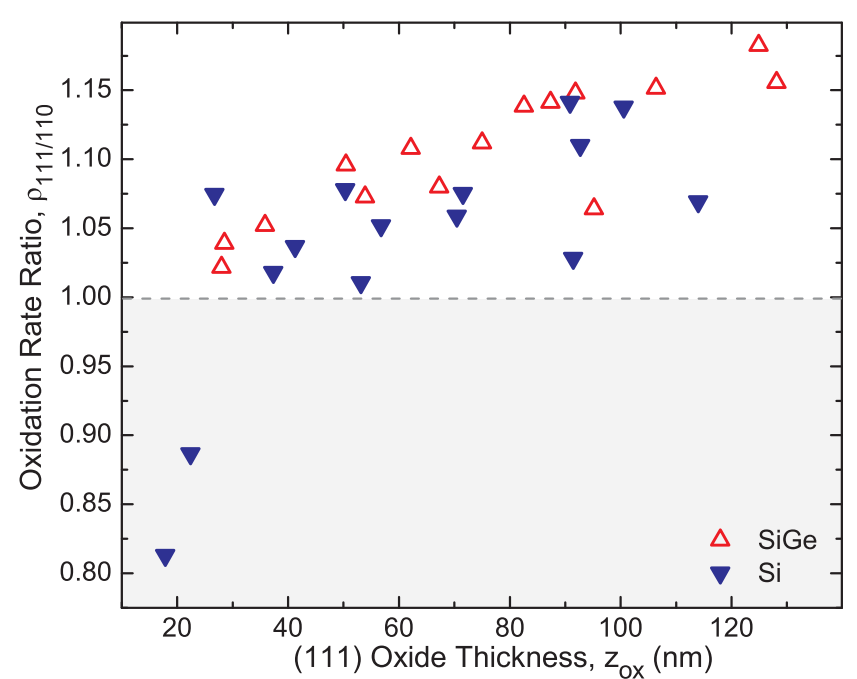

FIG. 8. Oxidation rate ratio, $\rho_{111 / 110}$, versus the oxide thickness of the (111) oriented sample, $z_{\mathrm{ox}}$.

difference in oxidation rates between orientations is not constant. This may be seen in Fig. 8, which shows the value of $\rho_{111 / 110}$ decreasing towards 1 as the oxide thickness decreases, and dropping below 1 for the two points with $z_{\text {ox }}<23 \mathrm{~nm}$. A crossover point around 20 to $25 \mathrm{~nm}$ and a positive slope is an indication that the oxidation proceeds from being controlled by the surface reaction rate at very small $z_{\mathrm{ox}}$, to being increasingly influenced by strain and the diffusivity of oxidant in the oxide as $z_{\text {ox }}$ increases.

It is well established that strain between the oxide and the underlying crystal reduces the oxidation rate. ${ }^{42,43,50,62-64}$ In addition to strain, the concept of steric hindrance is integral to explaining the orientation dependence of oxidation. While the number of surface bonds on differently oriented $\mathrm{Si}$ or SiGe follows the order $(110)>(111)>(100)$, the number of bonds available for an oxidation reaction due to steric hindrance follows the order $(111)>(110)>(100) .{ }^{41}$ On its own, the steric hindrance model predicts that the oxidation rates for dry $\mathrm{O}_{2}$ ambients will be ordered as (110) $>(111)>(100),{ }^{43}$ but, the magnitude of strain due to oxidation has also been shown to be a function of orientation, following the order $(111)<(100)<(110) .^{42}$ Taken together, the influence of steric hindrance and oxide strain result in orientation dependent oxidation rates being ordered as $(110)>(111)>(100)$ or $\quad(111)>(110)>(100)$, depending on the oxide thickness and oxidation conditions. ${ }^{41,43,50,63,64}$ The oxide thickness where the coupling of steric hindrance and oxide strain result in the oxidation rate order switching from $(110)>(111)$ to $(111)>(110)$ has been reported as being between 5 and $50 \mathrm{~nm},{ }^{42,43,64}$ which is consistent with the data from the present study.

There are a number physical mechanisms that are involved in oxidation of $\mathrm{Si}$ and $\mathrm{SiGe}$, including point defect generation, ${ }^{36,65}$ bond strength, ${ }^{31,34}$ steric hindrance, ${ }^{41}$ oxide strain, ${ }^{50,63}$ oxidant ambient, ${ }^{25}$ and diffusivity of $\mathrm{Si}$ in SiGe. ${ }^{25-27}$ It is difficult to quantitatively differentiate between various effects and their influence on Ge induced oxidation rate enhancement or reduction. However, if Arrhenius like behaviour for $\nu$ is presumed, their various

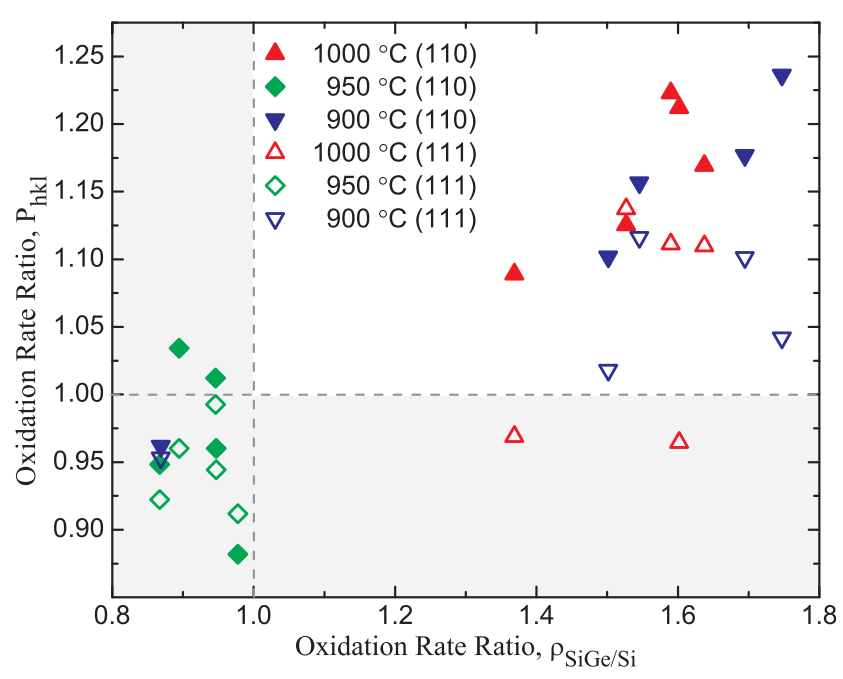

FIG. 9. The oxidation rate ratio between $\mathrm{SiGe}$ and $\mathrm{Si}$ samples of two orientations, $P_{h k l}=\left(\nu_{\mathrm{Si}}^{h k l} * \nu_{\mathrm{SiGe}}^{100}\right) /\left(\nu_{\mathrm{Si}}^{100} * \nu_{\mathrm{SiGe}}^{h k l}\right)$, versus the oxidation rate ratio between $\mathrm{SiGe}$ and $\mathrm{Si}$ for the $(100)$ orientation, $\rho_{\mathrm{SiGe} / \mathrm{Si}}=\nu_{\mathrm{SiGe}}^{100} / \nu_{\mathrm{Si}}^{100}$. The data are labeled according to the oxidation temperature and the sample orientation $(h k l)$ used to calculate $P$.

influences will be integrated into the values of $\nu_{0}$ and $E_{\mathrm{ox}}$ and can be eliminated by considering the ratio of the oxidation rates of similar samples. For example, the influence of $\mathrm{Ge}$ on the oxidation rate can be removed by considering $\nu_{\mathrm{SiGe}}^{111} / \nu_{\mathrm{SiGe}}^{100}$, while the influence of steric hindrance may be eliminated by considering $\nu_{\mathrm{SiGe}}^{111} / \nu_{\mathrm{Si}}^{111}$. It follows that the ratio of oxidation rates for both $\mathrm{Si}$ and $\mathrm{SiGe}$ samples of two orientations, $P=\left(\nu_{\mathrm{Si}}^{111} \nu_{\mathrm{SiGe}}^{100}\right) /\left(\nu_{\mathrm{Si}}^{100} \nu_{\mathrm{SiGe}}^{111}\right)$, should be equal to 1 . Such ratios comparing (111) and (110) to (100) for Si and SiGe are shown in Fig. 9 where they are plotted against $\rho_{\mathrm{SiGe} / \mathrm{Si}}$. It should be emphasized that each data point represents a group of samples that were oxidized simultaneously, and as such, have identical oxidation times, temperatures, and oxidant ambients. Those oxidation runs that resulted in growth rate reduction $\left(\rho_{\mathrm{SiGe} / \mathrm{Si}}<1\right)$ show $P \approx 1$, while those oxidation runs that resulted in growth rate enhancement $\left(\rho_{\mathrm{SiGe} / \mathrm{Si}}>1\right)$ show $P \gg 1$. This is an indication that simple modification of the linear rate constants may not be sufficient to model the influence of $\mathrm{Ge}$ on the oxidation rate.

\section{CONCLUSIONS}

The results of single and multiple oxidations have confirmed the strong and predictable temperature dependence of Ge content in the pile-up layer, and its relatively weak dependence on the Ge content in the underlying SiGe. Lower oxidation temperatures have been shown to be linearly correlated to higher Ge contents. Furthermore, the possibility to increase, maintain unaffected, or to decrease Ge content at the oxidation interface by manipulating the oxidation temperature has been demonstrated. The influence of crystallographic orientation on the oxidation rate of $\mathrm{SiGe}$ and the $\mathrm{Ge}$ content in the pile-up region has been examined. The redistribution of Ge in oxidizing SiGe has been characterized and explained by the balance of the fluxes of Si due to diffusion through the pile-up layer and incorporation into the oxide. X-ray diffraction and variable angle spectroscopic 
ellipsometry measurements have been used along with an empirical relation for the Ge content in the pile-up region to determine the diffusivity of $\mathrm{Si}$ in $\mathrm{SiGe}$ for the three orientations. The orientation dependence of the oxidation rate of SiGe was found to follow the order $(111)>(110)>(100)$, while the magnitude of the oxidation rate ratios between orientations is a function of the oxide thickness. The presence of $\mathrm{Ge}$ at the oxidation interface may have either a catalytic or inhibitive effect on the oxidation rate of SiGe; any such Ge induced oxidation rate enhancement or retardation will be subject to a number of factors, including point defect generation, bond strengths, steric hindrance, oxide strain, oxidant ambient, and the diffusivity of Si in SiGe.

\section{ACKNOWLEDGMENTS}

The Norwegian Research Council (via the FRINAT program) and CNRS are gratefully acknowledged.

${ }^{1}$ J. N. Aqua, I. Berbezier, L. Favre, T. Frisch, and A. Ronda, Phys. Rep. 522, 59 (2013).

${ }^{2}$ Y. Kim, M. Yokoyama, N. Taoka, M. Takenaka, and S. Takagi, in IEEE Photonics Conference (2011), pp. 465-466.

${ }^{3}$ L. Cao, J.-S. Park, P. Fan, B. Clemens, and M. L. Brongersma, Nano Lett. 10, 1229 (2010).

${ }^{4}$ M. Kolahdouz, A. A. Farniya, M. Östling, and H. H. Radamson, ECS Trans. 33, 221 (2010).

${ }^{5}$ A. H. Z. Ahmed and R. N. Tait, J. Appl. Phys. 94, 5326 (2003).

${ }^{6}$ M. Kanoun, A. Souifi, S. Decossas, C. Dubois, G. Bremond, F. Bassani, Y. Lim, A. Ronda, I. Berbezier, O. Kermarrec, and D. Bensahel, MRS Proc. 776, Q11.34 (2003).

${ }^{7}$ A. G. Novikau and P. I. Gaiduk, Cent. Eur. J. Phys. 8, 57 (2010).

${ }^{8}$ N. Singh, K. D. Buddharaju, S. K. Manhas, A. Agarwal, S. C. Rustagi, G. Q. Lo, N. Balasubramanian, and D.-L. Kwong, IEEE Trans. Electron Devices 55, 3107 (2008).

${ }^{9}$ S. Balakumar, K. D. Buddharaju, B. Tan, S. C. Rustagi, N. Singh, R. Kumar, G. Q. Lo, S. Tripathy, and D. L. Kwong, J. Electron. Mater. 38, 443 (2009).

${ }^{10}$ T.-Y. Liow, K.-M. Tan, Y.-C. Yeo, A. Agarwal, A. Du, C.-H. Tung, and N. Balasubramanian, Appl. Phys. Lett. 87, 262104 (2005).

${ }^{11}$ J. Hållstedt, P. E. Hellström, and H. H. Radamson, Thin Solid Films 517, 117 (2008)

${ }^{12}$ E. Sutter, F. Camino, and P. Sutter, Appl. Phys. Lett. 94, 083109 (2009).

${ }^{13}$ F.-J. Ma, B. S. Chia, S. C. Rustagi, and G. C. Samudra, in ESciNano, International Conference on Enabling Science and Nanotechnology (2010), pp. 1-2.

${ }^{14}$ L. Zhang, M. d'Avezac, J.-W. Luo, and A. Zunger, Nano Lett. 12, 984 (2012).

${ }^{15}$ M. Palummo, M. Amato, and S. Ossicini, Phys. Rev. B 82, 073305 (2010).

${ }^{16}$ X. Peng, F. Tang, and P. Logan, J. Phys.: Condens. Matter 23, 115502 (2011).

${ }^{17}$ K.-W. Ang, K.-J. Chui, A. Madan, L.-Y. Wong, C.-H. Tung, N. Balasubramanian, M.-F. Li, G. S. Samudra, and Y.-C. Yeo, IEEE Electron Device Lett. 28, 509 (2007).

${ }^{18}$ C. Le Royer, Microelectron. Eng. 88, 1541 (2011).

${ }^{19}$ S. Nakaharai, T. Tezuka, N. Hirashita, E. Toyoda, Y. Moriyama, N. Sugiyama, and S. Takagi, J. Appl. Phys. 105, 024515 (2009).

${ }^{20}$ K. Kutsukake, N. Usami, K. Fujiwara, T. Ujihara, G. Sazaki, B. Zhang, Y. Segawa, and K. Nakajima, Jpn. J. Appl. Phys., Part 2 42, L232 (2003).

${ }^{21}$ Z. Di, P. K. Chu, M. Zhang, W. Liu, Z. Song, and C. Lin, J. Appl. Phys. 97, 064504 (2005).

${ }^{22}$ F. K. LeGoues, R. Rosenberg, T. Nguyen, F. Himpsel, and B. S. Meyerson, J. Appl. Phys. 65, 1724 (1989).

${ }^{23}$ M. Spadafora, G. Privitera, A. Terrasi, S. Scalese, C. Bongiorno, A. Carnera, M. Di Marino, and E. Napolitani, Appl. Phys. Lett. 83, 3713 (2003).

${ }^{24}$ M. A. Rabie, Y. M. Haddara, and J. Carette, J. Appl. Phys. 98, 074904 (2005).
${ }^{25}$ S. J. Kilpatrick, R. J. Jaccodine, and P. E. Thompson, J. Appl. Phys. 81, 8018 (1997).

${ }^{26}$ E. Long, A. Azarov, F. Kløw, A. Galeckas, A. Y. Kuznetsov, and S. Diplas, J. Appl. Phys. 111, 024308 (2012).

${ }^{27}$ E. Long, A. Galeckas, and A. Y. Kuznetsov, J. Vac. Sci. Technol. B 30, 041212 (2012).

${ }^{28}$ J. H. Jang, S. Y. Son, W. Lim, M. S. Phen, K. Siebein, S. J. Pearton, and V. Craciun, Appl. Phys. Lett. 94, 202104 (2009).

${ }^{29}$ I. Berbezier, M. Aouassa, A. Ronda, L. Favre, A. Delobbe, and P. Sudraud "Nanofabrication of core-shell Sil-xGex/Ge nanowires, submitted to Nanotechnology" (unpublished).

${ }^{30}$ A. Y. Kuznetsov, H. H. Radamson, B. G. Svensson, W. X. Ni, G. V. Hansson, and A. Nylandsted Larsen, Phys. Scr. T79, 202 (1999).

${ }^{31}$ J. P. Zhang, P. L. F. Hemment, S. M. Newstead, A. R. Powell, T. E. Whall, and E. H. C. Parker, Thin Solid Films 222, 141 (1992).

${ }^{32}$ O. W. Holland, C. W. White, and D. Fathy, Appl. Phys. Lett. 51, 520 (1987).

${ }^{33}$ T. Shimura, Y. Okamoto, T. Inoue, T. Hosoi, and H. Watanabe, Phys. Rev. B 81, 033308 (2010).

${ }^{34}$ A. R. Srivatsa, S. Sharan, O. W. Holland, and J. Narayan, J. Appl. Phys. 65, 4028 (1989).

${ }^{35}$ T. Shimura, Y. Okamoto, D. Shimokawa, T. Inoue, T. Hosoi, and H. Watanabe, ECS Trans. 33, 893 (2010).

${ }^{36}$ F. K. LeGoues, R. Rosenberg, and B. S. Meyerson, Appl. Phys. Lett. 54, 644 (1989).

${ }^{37}$ D. Nayak, K. Kamjoo, J. C. S. Woo, J. S. Park, and K. L. Wang, Appl. Phys. Lett. 56, 66 (1990).

${ }^{38}$ F. K. LeGoues, R. Rosenberg, and B. S. Meyerson, Appl. Phys. Lett. 54, 751 (1989).

${ }^{39}$ E. Long, A. Galeckas, and A. Y. Kuznetsov, Phys. Status Solidi A 209, 1934 (2012)

${ }^{40}$ S. Margalit, A. Bar-Lev, A. B. Kuper, H. Aharoni, and A. Neugroschel, J. Cryst. Growth 17, 288 (1972).

${ }^{41}$ J. R. Ligenza, J. Phys. Chem. 65, 2011 (1961).

${ }^{42}$ E. Kobeda and E. A. Irene, J. Vac. Sci. Technol. B 5, 15 (1987).

${ }^{43}$ E. A. Lewis and E. A. Irene, J. Electrochem. Soc. 134, 2332 (1987).

${ }^{44}$ G. Masetti, S. Solmi, and G. Soncini, Solid-State Electron. 19, 545 (1976).

${ }^{45}$ P. M. Fahey, P. B. Griffin, and J. D. Plummer, Rev. Mod. Phys. 61, 289 (1989).

${ }^{46}$ A. Seeger, Phys. Status Solidi B 248, 2772 (2011).

${ }^{47}$ J. P. Dismukes, L. Ekstrom, and R. J. Paff, J. Phys. Chem. 68, 3021 (1964).

${ }^{48}$ C. M. Herzinger, B. Johs, W. A. McGahan, J. A. Woollam, and W. Paulson, J. Appl. Phys. 83, 3323 (1998).

${ }^{49}$ J. Humlíček, M. Garriga, M. I. Alonso, and M. Cardona, J. Appl. Phys. 65, 2827 (1989).

${ }^{50}$ W. A. Pliskin, IBM J. Res. Dev. 10, 198 (1966).

${ }^{51}$ E. A. Irene, J. Electrochem. Soc. 121, 1613 (1974).

${ }^{52}$ H. Z. Massoud and J. D. Plummer, J. Appl. Phys. 62, 3416 (1987).

${ }^{53}$ E. H. Nicollian and J. R. Brews, MOS (Metal Oxide Semiconductor) Physics and Technology, Wiley Classics Library (Wiley-Interscience, 2002), pp. 645-707.

${ }^{54}$ R. Kube, H. Bracht, J. Lundsgaard Hansen, A. Nylandsted Larsen, E. E. Haller, S. Paul, and W. Lerch, J. Appl. Phys. 107, 073520 (2010).

${ }^{55}$ S. I. Raider, R. A. Gdula, and J. R. Petrak, Appl. Phys. Lett. 27, 150 (1975).

${ }^{56}$ C. Tètelin, X. Wallart, J. P. Nys, L. Vescan, and D. J. Gravesteijn, J. Appl. Phys. 83, 2842 (1998).

${ }^{57}$ J. M. Madsen, Z. Cui, and C. G. Takoudis, J. Appl. Phys. 87, 2046 (2000).

${ }^{58}$ Y. S. Lim, F. Bassani, A. Portavoce, A. Ronda, S. Nozaki, and I. Berbezier, Mater. Sci. Eng., B 101, 190 (2003).

${ }^{59}$ J. Xiang, N. Herbots, H. Jacobsson, P. Ye, S. Hearne, and S. Whaley, J. Appl. Phys. 80, 1857 (1996).

${ }^{60}$ Z. Atzmon, A. E. Bair, T. L. Alford, D. Chandrasekhar, D. J. Smith, and J. W. Mayer, Appl. Phys. Lett. 66, 2244 (1995).

${ }^{61}$ E. J. Jaquez, A. E. Bair, and T. L. Alford, Appl. Phys. Lett. 70, 874 (1997).

${ }^{62}$ A. Fargeix and G. Ghibaudo, J. Appl. Phys. 54, 7153 (1983).

${ }^{63}$ D.-B. Kao, J. P. McVittie, W. D. Nix, and K. C. Saraswat, IEEE Trans. Electron Devices 34, 1008 (1987).

${ }^{64}$ K. Imai and K. Yamabe, MRS Proc. 239, 107 (1991).

${ }^{65}$ M. Uematsu, H. Kageshima, and K. Shiraishi, Comput. Mater. Sci. 24, 229 (2002). 